\title{
The Thermoelectric Properties of Electrochemically Deposited Te-Sb-Bi Films on ITO Glass Substrate
}

\author{
Chao-Kai Yang ${ }^{*}$, Tsung-Chieh Cheng, Tao-Hsing Chen", Shih-Hua Chu \\ Department of Mechanical Engineering, National Kaohsiung University of Applied Sciences, \\ Kaohsiung 807, Taiwan \\ *E-mail: ck1114.yang@gmail.com; thchen@cc.kuas.edu.tw
}

doi: $10.20964 / 110371$

Received: 15 January 2016 / Accepted: 29 February 2016 / Published: 1 April 2016

In this study, we use ITO glass to deposit thermoelectric thin films by using electrochemically deposition method. With electrochemical deposition, we deposit Te-Bi-Sb thin films on ITO glasses, trying to probe into different influences on thermoelectric characteristics by changing $\mathrm{Sb}^{3+}$ consistency and current density. The finished Te-Bi-Sb thin films will be observed by Scanning Electron Microscope (SEM) to realize the microstructure, also, be identified the crystal structure with XRD, and electrical analysis. The result finds out the thin film is a P-type thermoelectric material. Owing to the variation of current density or electrolyte density affects and changes the structure of Te-Bi-Sb film, the study categorizes three types of forming structures: Ball-type, Mixed-type, and Acicular-type; the ion content of the precipitated film can be controlled by alter current or electrolyte density. Good thermoelectric material requires high Seebeck coefficient, and the best one in the study is in the condition of $38 \mathrm{mM}-2.1 \mathrm{~mA} / \mathrm{cm}^{2}$, which results in $32.89 \mu \mathrm{V} / \mathrm{K}$. Also, power factor is a criterion to evaluate a material, and bigger factor equals to better quality. In this study, we get the best power factor in the condition of $15 \mathrm{mM}-2.1 \mathrm{~mA} / \mathrm{cm}^{2}$, with the result of $49.5505 \alpha^{2} / \rho$.

Keywords: Electrodeposition, Thermoelectric thin film, Seebeck

\section{FULL TEXT}

(C) 2016 The Authors. Published by ESG (www.electrochemsci.org). This article is an open access article distributed under the terms and conditions of the Creative Commons Attribution license (http://creativecommons.org/licenses/by/4.0/). 